\title{
Geothermal energy in the UK: the life-cycle environmental impacts of electricity production from the United Downs Deep Geothermal Power project
}

\author{
Word count: 7779
}

\begin{abstract}
The UK is rich in heat-producing granites, especially in the county of Cornwall, suggesting the potential for energy production with low environmental footprint. The United Downs Deep Geothermal Power (UDDGP) project aims to demonstrate the technical and commercial viability to produce electricity from the Cornish geothermal resource, exploiting the natural permeability of a significant deep structural fracture zone known as the Porthtowan Fault Zone. Drilling of the first well started at the end of 2018, and the plant is expected to be operational by mid-2020. A relevant question is whether deep geothermal energy is truly environmentally benign. This article presents a comprehensive and detailed Life Cycle Assessment study that i) identifies the main life-cycle sources of environmental impacts for the production of electricity in the UDDGP plant; ii) investigates the effects on the environmental impacts of significant uncertainties surrounding the project, such as availability of geothermal fluid and configuration of the power plant, and iii) compares the performance of the UDDGP operation, and by extension of the putative geothermal energy production in the UK, with other key energy sources in the country. The life cycle inventory relies on a combination of site-specific data for wells construction and literature data for above-surface facilities and stimulation techniques. We validated our model by comparing climate change impacts of UDDGP with those reported by other studies on enhanced geothermal systems. Our results show that the greatest portion of environmental impacts originates from the construction phase (primarily due to steel for wells casing and diesel used during drilling), whilst the scenario analysis demonstrates that increasing installed capacity and cogenerating heat and power are the most effective strategies for improving the environmental performance. Our analysis also suggests that the environmental impacts may increase by $\sim 35 \%$ if stimulation techniques are required to increase the geothermal wells productivity. Compared to alternative energy sources, in the category climate change, UDDGP performs better than solar energy and is comparable with wind and nuclear. It is shown that the environmental benefits of geothermal energy are not straightforward and that a number of trade-offs needs to be considered when other impact categories are quantified.
\end{abstract}

Keywords: Life Cycle Assessment; environmental impacts; geothermal energy; enhanced geothermal systems.

\section{Highlights}

- Comprehensive LCA on the first deep geothermal power plant in the UK.

- Steel and diesel consumption are the greatest source of environmental impacts.

- Stimulation techniques can increase the environmental impacts by as much as $35 \%$.

- Cogeneration and higher installed capacity improve the environmental performance.

- Deep geothermal energy in the UK has better performance than solar. 


\section{Introduction}

The contribution of geothermal energy to global power generation remains minute, but the sector is set to play, alongside other emerging and established renewable technologies, a key role in meeting carbon emissions targets such as those set by the Paris Agreement in 2015 (UNFCCC, 2015). Presently geothermal energy contributes to around $0.3 \%$ (87 TWh) of global electricity production (IEA, 2018); the International Energy Agency predicts production of electricity from the geothermal source to increase fivefold by 2040 if the Paris Agreement target is to be met (IEA, 2018).

Geothermal plants are concentrated in tectonically active countries such as Iceland, Italy and New Zealand. These plants harness the heat stored in high-enthalpy natural aquifers to produce electricity by means of dry steam, single flash and double flash technologies. Deep and enhanced geothermal plants represent more recent technologies that target heat stored in the rock at depths greater than natural aquifers by either relying on the presence of geothermal fluid and enough permeability, or by injecting water to artificially increase the permeability and extract heat from the rocks. The advantage of these systems is that they enable extraction of geothermal energy from practically anywhere although current technology restricts economical exploration to locations with significant thermal gradients, such the Upper Rhine Valley on the French-German boundary and the Cooper Basin in Queensland, Australia (Lu, 2018; MIT, 2006).

Being tectonically inactive, the UK lacks high-enthalpy hydrothermal reservoirs. However, it is rich in heat-producing granites, especially in Cornwall, where heat flow is approximately double the UK average (Busby and Terrington, 2017). Granites contain small quantities of radioactive potassium, thorium and uranium that decay over periods of billions of years, and in doing so produce heat. However, they are typically not porous, and therefore not permeable unless fractured. Some of the UK granites are naturally fractured as a result of earth movements that have occurred since their emplacement; others could be stimulated to transmit fluids (Busby and Terrington, 2017). The technical potential of energy production from the geothermal source in the UK is considerable and ranges between 1 and $10 \mathrm{GW}$ ( 3-30\% of national electricity generation), the majority of which is located in Cornwall (Busby and Terrington, 2017; SKM Consulting, 2011).

The United Downs Deep Geothermal Power (UDDGP) is the first geothermal power project in the UK. The project aims to demonstrate the technical and commercial viability of producing electricity from heat produced by the Cornish granites, exploiting the natural permeability of a significant structural fracture zone known as the Porthtowan Fault Zone (Ledingham et al., 2019). Drilling of the first geothermal well started in 2018. The envisaged completion of the wells is by the end of 2019, followed by a period of testing of both wells and reservoir. Assuming the tests are successful, commissioning of the power plant is expected to occur during the second half of 2020.

While it is generally expected that producing energy from geothermal sources has a reduced carbon footprint compared to traditional processes such as coal and other fossil fuels, a detailed quantification of other environmental impacts is imperative to enable the community, and the society at large, to decide whether to pursue this energy source. Life Cycle Assessment (LCA) studies are useful to this end because they cover a number of environmental issues and enable identification of tradeoffs between alternatives (an introduction to the LCA methodology is given in Hauschild et al., 2017). In recent years, numerous studies have been performed on deep and enhanced geothermal plants (e.g. Frick et al., 2010; Lacirignola and Blanc, 2013; Pratiwi et al., 2018; Sullivan et al., 2011, 2010; Treyer et al., 2015) and on conventional geothermal plants (Bravi and Basosi, 2014; Parisi et al., 2019; Paulillo et al., 2019d; Sullivan et al., 2011, 2010) around the world. A review of LCA studies on geothermal power generation technologies is found in Tomasini-Montenegro et al. (2017). 
This article presents a comprehensive prospective attributional Life Cycle Assessment (LCA) study that uses site-specific data to quantify the potential environmental impacts of electricity generation from the first geothermal plant in the UK. The study investigates several realistic scenarios to account for uncertainties related to the completion and the operation of the geothermal plant, and compares the environmental performance of deep geothermal energy in the UK with alternative and renewable energy sources. The objective is to provide possible recommendations to improve the environmental performance from deep geothermal energy, and valuable information to policy-makers and the public alike on the potential environmental trade-offs of such energy source.

The article is organised as follows: Section 2 introduces the UDDGP concept and presents the main parameters of the LCA study, including goal and scope, life cycle inventory, scenarios and impact categories analysed. The results of the LCA study are reported in Section 3 and discussed in Section 4. Key conclusions are summarised in Section 5.

\section{Methods}

\subsection{The UDDGP concept}

The UDDGP concept, depicted in Figure 1Error! Reference source not found., relies on establishing circulation over a large vertical distance through the natural fracture system within the Porthtowan Fault Zone, by means of a downhole pump and two deep, deviated wells. If the permeability is high enough, the large well separation $(2000 \mathrm{~m})$ will enable sufficient flow rate and heat transfer area for commercial energy extraction. Such permeability has been observed previously in other regions, but in the UK it remains to be tested (Ledingham et al., 2019).

According to the UDDGP plans, the deviated wells will intersect the fault zone at depths of 2500 and $4500 \mathrm{~m}$, with the production well beneath the injection well. This configuration is based on the surprising outcome of the Hot Dry Rock research project in Cornwall, which demonstrated that injected water migrated downwards rather than upwards in this formation (Parker, 1989). Circulation in the UDDGP system will be driven by a downhole pump in the production well, which will create a pressure sink around the well, drawing water towards it not only from the injection well but also from the far field. Based on earlier studies and heat flow modelling, temperature in the bottom hole is expected to be in the region of $190{ }^{\circ} \mathrm{C}$. The project aims to produce water to surface at a target temperature of $175{ }^{\circ} \mathrm{C}$ and circulate it in a binary cycle power plant to produce at least $1 \mathrm{MW}$ of electricity. The maximum capacity of the power plant is limited to $3 \mathrm{MW}$ by the existing connection to the grid.

The greatest uncertainty the UDDGP project faces concerns the existence and the extent of the fracture system, and the resulting availability of the geothermal fluid. Approaches to enhance geothermal fluid production such as construction of a two-legged well and hydraulic or chemical stimulation may be required to increase permeability and fluid transport. The configuration of the wells pumps may be subject to changes after wells completion and reservoir tests; for instance, downward migration of the injected fluid could be increased by using an injection pump. In this article we quantify how these uncertainties affect the expected environmental performance of the UDDGP project. 


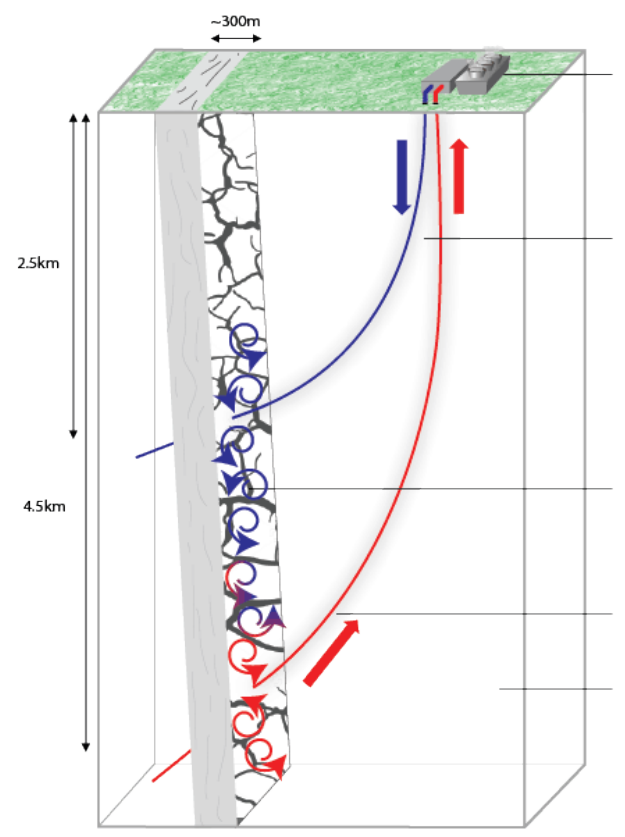

Figure 1 - Schematic of the UDDGP concept detailing the configuration of the two deep deviated wells intersecting the Porthtowan Fault Zone at 2.5 and $4.5 \mathrm{~km}$. The injection well is in blue and the production one in red. (Ledingham et al., 2019).

\subsection{Goal of the study}

This study quantifies the life-cycle environmental impacts of the electricity expected to be generated by the UDDGP plant following the Life Cycle Assessment (LCA) standardised methodology (ISO, 2006a, 2006b), and using Gabi software version 8 for computations, with a threefold goal:

- Identify the main hot-spots in the life-cycle and, where possible, suggest potential improvements;

- Investigate the effects of the project uncertainties by analysing a range of possible scenarios;

- Contextualize the environmental performance of geothermal energy in the UK through comparison with selected alternative and renewable energy sources.

To validate our model, we compare the climate change impacts of our study with those of other LCA studies on enhanced geothermal plants.

We adopt a prospective perspective (Sandén, 2007; Sandén et al., 2005) and an attributional approach (Curran et al., 2005; Finnveden et al., 2009). An LCA study of this type quantifies environmental impacts that will occur in the future (prospective perspective) without including the consequences of choices made based on the results of the study (attributional approach). The functional unit is $1 \mathrm{kWh}$ of electricity produced.

\subsection{Scope}

As shown in Figure 2, the system boundaries of the LCA study are cradle to grave and include the three phases of construction, operation and end of life. We adopt the distinction between foreground and background system, with the former defined as "the set of processes whose selection or mode of operation is affected directly by decisions based on the study" and the latter as "all other processes which interact with the foreground, usually by supplying or receiving material or energy" (Clift et al., 2000). 
The construction phase within the UDDGP project includes drilling of two shallow exploration wells and two deep deviated wells for injection and production, and building above-surface facilities including collection pipelines and a binary cycle power generating plant. The operational phase includes operation of well pumps, and of the power plant for producing electricity. We assume that the geothermal plant does not require any maintenance in the form of make-up wells. The end-of-life phase consists of closure of the geothermal wells and dismantling of the power plant.

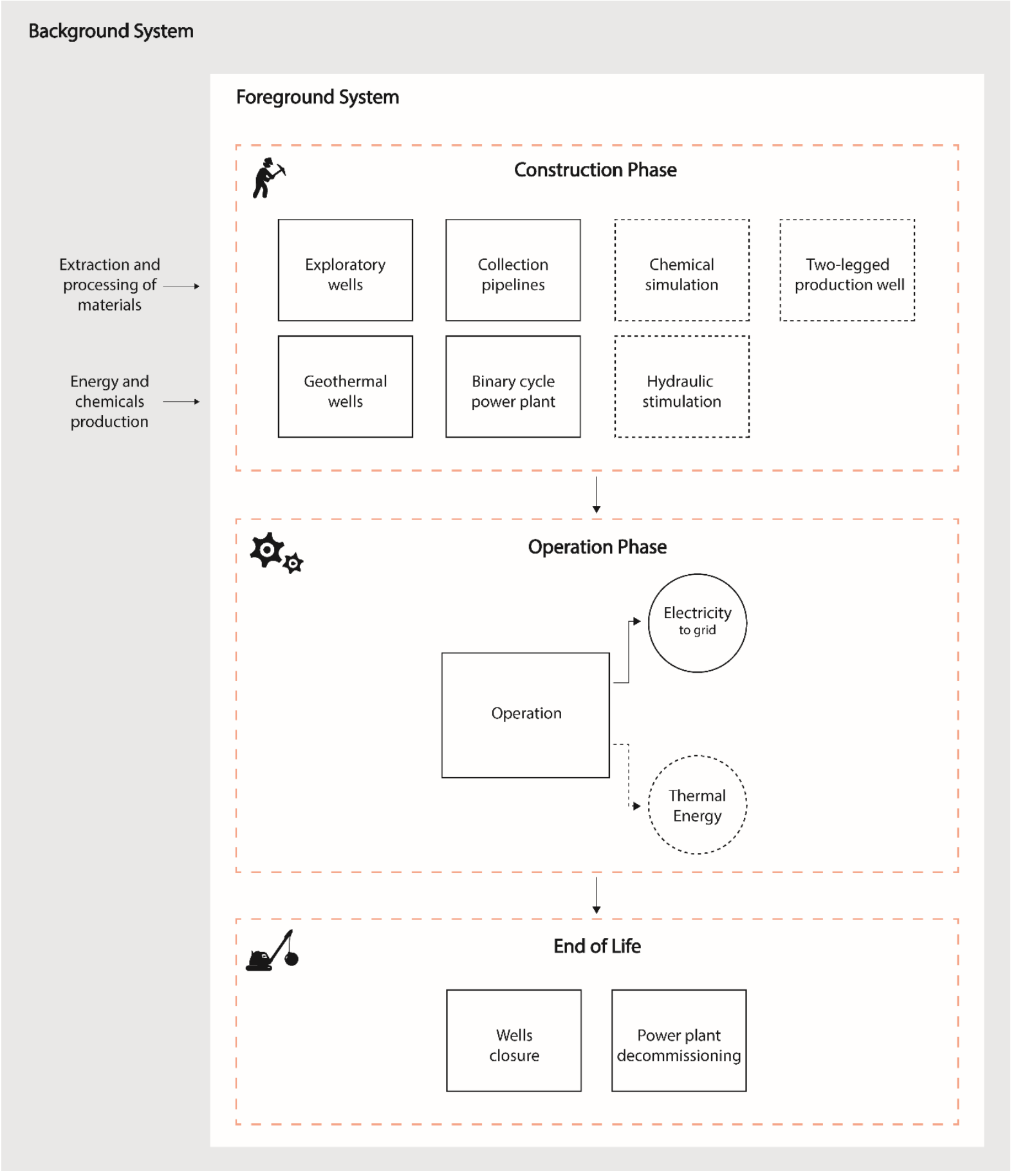

Figure 2 - System boundaries of the LCA study. Dashed boxes identify processes that are not part of the base case and that are considered in the alternative scenarios analysed. 


\subsection{Scenarios}

Table 1 reports the technical parameters of the geothermal wells and the power generation plant that are common to all scenarios analysed. At the outset of the project, two shallow exploratory wells were drilled at a depth of $200 \mathrm{~m}$ to analyse local geological features. The total length of the deep injection and production wells will measure 3000 and $5050 \mathrm{~m}$, respectively; this is longer than the depth at which the wells will intersect the Faults zone because parts of the wells are drilled with a substantial inclination (see Figure 1). The binary cycle power plant will use a working fluid in an organic Rankine cycle (ORC) and is expected to work with an inlet temperature of $175^{\circ} \mathrm{C}$ and an outlet of $90^{\circ} \mathrm{C}$. In this study we assume that the working fluid is perfluoropentane (Rogge, 2004) - note that the same assumption is made in the Ecoinvent database v3.4 primarily because of a lack of inventory data on other working fluids - and that no losses of working fluid occur during plant operation. Also, line with previous LCA studies we assume that the ORC yields a conversion efficiency from the geothermal fluid's thermal energy to gross electric power of 13\% (Frick et al., 2010; Lacirignola and Blanc, 2013; Pratiwi et al., 2018) and that auxiliary power demand of the plant is approximately $20 \%$ of the gross electricity produced (Lacirignola and Blanc, 2013). For the plant, we use a technical life time of 30 years and a load factor ${ }^{1}$ of 0.9 .

Table 1 - Technical parameters common to all scenarios considered in this study.

\begin{tabular}{lrl} 
PARAMETER & VALUE \\
\hline Geothermal wells length & $2 \times 200$ & $\mathrm{~m}$ \\
$\quad$ Exploratory & 3000 & $\mathrm{~m}$ \\
Injection & 5050 & $\mathrm{~m}$ \\
$\quad$ Production & & \\
Power plant & 175 & ${ }^{\circ} \mathrm{C}$ \\
Inlet temperature & 90 & ${ }^{\circ} \mathrm{C}$ \\
Outlet temperature & 13 & $\%$ \\
ORC efficiency & 20 & $\%$ \\
Auxiliary power & 300 & $\mathrm{~kg} / \mathrm{MW}$ \\
Working fluid: Perfluoropentane & 30 & years \\
Technical life time & 25 & $\mathrm{~m} / \mathrm{well}$ \\
Collection pipelines & 0.9 & -
\end{tabular}

In Table 2 we report the technical parameters that differentiate each scenario. In the base case scenario, we assume sufficient natural productivity of the geothermal wells ( $21 \mathrm{~kg} / \mathrm{s}$ ) to support an installed capacity of $1 \mathrm{MW}$ by using a downhole pump and without having to resort to stimulation. Because the power absorbed by the downhole pump depends on many interdependent parameters, we introduce the simplified hypothesis that this equals to $1.5 \mathrm{~kW} /\left(\mathrm{m}^{3} / \mathrm{h}\right)$. In this scenario, net electricity production equals $0.67 \mathrm{MJ} / \mathrm{s}$.

We developed four scenarios that explore the possibility that some type of stimulation is required to reach the target productivity. We assume that first chemical stimulation is carried out to remove nearwellbore permeability damage and material deposited in factures through dissolution by means of acid injection (scenario St_C). If chemical stimulation is not sufficient to reach the target productivity, then either construction of a two-legged production well (St_C_2L) or hydraulic stimulation (St_C_H) may be carried out. The second leg starts at the kick-off point for deviated drilling and proceeds 500 $\mathrm{m}$ deeper so that the two wells intersect the fault zone with a vertical distance of $500 \mathrm{~m}$. Hydraulic stimulation increases the well productivity by fracturing the rocks by means of high-pressure of a fracking fluid, which is primarily made of water. Finally, in the fourth scenario (St_C_2L_H) we

\footnotetext{
${ }^{1}$ The load factor is the ratio of the amount of time the plant produces electricity and the total available time over the plant technical lifetime.
} 
investigate the possibility that acid injection, a two-legged production well, as well as chemical stimulation are all required to yield the desired target productivity.

We developed three further scenarios on alternative configurations of the wells pumps that include i) the downhole pump is not required ( $\left.P_{-} N\right)$, ii) only a reinjection pump is required $\left(P_{-} R\right)$, and iii) both a reinjection and a downhole pump are required $\left(P_{-} D+R\right)$. In the two final scenarios (namely $3 \mathrm{MW}$ and Cogen), we investigate the possibility that the productivity of the wells is high enough $(\sim 63 \mathrm{~kg} / \mathrm{s})$ to support an installed capacity of $3 \mathrm{MW}$, and that the plant produces thermal energy besides electricity. For the latter we use an exergy-based partitioning factor of 0.45 to allocate the environmental impacts between the functions of electricity and thermal energy production (reported in Paulillo et al., 2019c). 
Table 2 - Parameters for each scenario analysed in this study.

\section{PARAMETER}

\section{Geo-fluid flow rate}

Chemical stimulation

Hydraulic stimulation

2nd-leg

Downhole pump ${ }^{2}$

Reinjection pump ${ }^{2}$

Net plant output

Total heat production

Notes:
UNIT

$$
\mathrm{kg} / \mathrm{s}
$$

$\mathrm{m}^{3}$ of water

$\mathrm{m}^{3}$ of water

$m$ drilled

kW

kW

$\mathrm{MJ} / \mathrm{s}$

$\mathrm{MJ} / \mathrm{s}$

$\begin{array}{ccc}\text { Base case } & \text { St_C } & \text { St } \\ 21.1 & 21.1 & 21 \\ 0 & 6000 & 600 \\ 0 & 0 & \\ 0 & 0 & 255 \\ 128 & 128 & 128 \\ 0 & 0 & \\ 0.67 & 0.67 & 0.67 \\ 0 & 0 & 0\end{array}$

$\begin{array}{cc}\text { St_C_2L } & \text { St_C_H } \\ 21.1 & 21.1 \\ 6000 & 6000 \\ 0 & 20000 \\ 2550 & 0 \\ 128 & 128 \\ 0 & 0 \\ 0.67 & 0.67 \\ 0 & 0\end{array}$

SCENARIO

\begin{tabular}{cccccc} 
St_C_2L_H & P_N & P_R & P_D+R & $3 \mathrm{MW}$ & Cogen \\
21.1 & 21.1 & 21.1 & 21.1 & 63.4 & 21.1 \\
6000 & 0 & 0 & 0 & 0 & 0 \\
20000 & 0 & 0 & 0 & 0 & 0 \\
2550 & 0 & 0 & 0 & 0 & 0 \\
128 & 0 & 0 & 128 & 385 & 128 \\
0 & 0 & 88.4 & 88.4 & 0 & 0 \\
0.67 & 0.80 & 0.71 & 0.58 & 2.02 & 0.67 \\
0 & 0 & 0 & 0 & 0 & 3.54 \\
\hline
\end{tabular}

(2008) and Schindler et al. (2010) and are reported in full in Paulillo et al. (2019c).

${ }^{2}$ Calculation of pumps power demand is based on an estimated specific consumption of 1.5 and $1 \mathrm{~kW} /(\mathrm{m} 3 / \mathrm{h})$ for downhole and reinjection pumps respectively. 


\subsection{Life cycle inventory}

The foreground system relies on a combination of site-specific and literature data. We use site-specific data derived from UDDGP wells' design to describe drilling and completion of exploratory and primary wells, including the case of a two-legged production well. Key materials requirements for the geothermal wells are reported in Table 3, and complete inventories are reported in Paulillo et al. (2019c).

The remaining processes rely on literature data. Construction of the above-surface facilities, which include the power plant and the collection pipelines, is based on the life cycle inventory developed by Karlsdóttir and colleagues (2015); notably, we make the simplifying assumption that the material requirements of the binary cycle plant are equivalent to that of the single-flash plant in Karlsdóttir et al. (2015). Treatment of drilling waste is based on the Ecoinvent database and assumed disposal in a residual material landfill (Doka, 2003); material requirements for the wells pumps, which include their maintenance, are obtained from Frick et al. (2010); and the inventory for chemical and hydraulic stimulation techniques (reported in full in Paulillo et al. (2019c) and as amount of water per well in Table 3 ) is based on data reported concerning the European EGS project at Soultz-sous-Forêts (Lacirignola and Blanc, 2013; Nami et al., 2008; Schindler et al., 2010).

The end-of-life phase is based on the Ecoinvent database version 3.4 (Wernet et al., 2016), and envisages that geothermal wells are filled with cement and gravel, and sealed with a concrete slab, and that materials from the decommissioning of above-surface facilities are treated in line with the average trend of the market, by using the Ecoinvent market activities.

Table 3 - Key material requirements for drilling and completion of geothermal wells.

\begin{tabular}{|c|c|c|c|c|}
\hline & & INJECTION & PRODUCTION & PRODUCTION LEG2* \\
\hline Fuel & $\mathrm{GJ} / \mathrm{m}$ & 7.23 & 7.23 & 7.23 \\
\hline Cement $^{1}$ & $\mathrm{~kg} / \mathrm{m}$ & 42.32 & 16.02 & 8.70 \\
\hline Steel & $\mathrm{kg} / \mathrm{m}$ & 84.30 & 76.46 & 46.83 \\
\hline Drilling mud ${ }^{2}$ & $\mathrm{~m}^{3} / \mathrm{m}$ & 0.54 & 0.51 & 0.65 \\
\hline Drilling waste & ton & 1143 & 1807 & 610 \\
\hline
\end{tabular}

\subsection{Impact assessment}

We use the ILCD (International Life Cycle Data System) mid-points approach to translate life cycle emissions and resources use into environmental impacts (JRC, 2012, 2011). We include all impact categories with the sole exclusion of ionising radiations, for which we use a more recent and comprehensive category developed by (Paulillo et al., 2019a, 2019b) and Paulillo (2018). Table 4 and Table S1 in the Supporting Information report the impact categories considered in this study along with their metrics. A brief description of each category is included in the Supporting Information.

Within the main paper, we focus on six impact categories (Table 4); these have been selected based on their normalised impacts (reported in Figure S1 in the Supporting Information) calculated according to the ILCD method (Benini et al., 2014) and Paulillo (2018), which represent the contributions to the overall impact per person of Europe. 
Table 4 - Impact categories analysed reported in the article.

\begin{tabular}{ll} 
IMPACT CATEGORY & METRIC \\
\hline Climate change & $\mathrm{kg} \mathrm{CO} 2 \mathrm{eq}$. \\
Ecotoxicity freshwater & CTUe \\
Human toxicity, cancer effects & CTUh \\
Human toxicity, non-cancer effects & CTUh \\
Particulate matter/respiratory inorganics, human health & $\mathrm{kg} \mathrm{PM2.5} \mathrm{eq.}$ \\
Photochemical ozone formation, human health & $\mathrm{kg} \mathrm{NMVOC}$ \\
\hline
\end{tabular}

\section{Results}

\subsection{Hot-spot and scenario analysis}

In Figure 3 we report the hot-spot analysis for the base case scenario and a comparison of the performance of the nine alternative scenarios, which were introduced in Section 2.4. The hot-spot analysis includes both production/construction and end-of-life treatment of the main elements that make up the product system (Figure 2); these include production and injection wells, collection pipelines and the binary cycle power plant. The comparison with the alternative scenarios is expressed in terms of percentage variation from the base case.

For the base case scenario, the chart shows that production and injection wells contribute to nearly $80 \%$ of the ecotoxicity freshwater impact and over $80 \%$ of the other impact categories. The power plant yields a contribution of $\sim 20 \%$ to the ecotoxicity freshwater category, lower contributions of the order of $15 \%$ to human toxicity categories, and only minor contributions to the remaining categories reported in the article. The power plant also has significant contributions ( $20 \%)$ - which are almost entirely attributable to the production of perfluoropentane and its treatment after closure of the plant - to the Ozone Depletion amongst the categories included in the Supporting Information. The overall impact to the toxicity categories is dominated by emissions of metals, whose characterisation factors are notoriously affected by high uncertainties (e.g. see Pizzol et al., 2011). These include chromium, zinc and copper (see Figure S2 in the Supporting Information) and originate from the production of steel and the treatment of drilling waste.

In Figure 4 we report a detailed hot-spot analysis on the production well. This shows that steel, primarily that used for the well casing, and diesel, used during the drilling process, are the dominant contributions to all impact categories. Disposal of drilling waste (cuttings) yields contributes to $10-20 \%$ of the toxicity categories. Drilling mud, concrete and spacer ${ }^{2}$ used during wells drilling, wellhead and wells closure, and steel for the downhole pump yield negligible impacts.

With respect to the alternative scenarios that envisage use of stimulation techniques, Figure 3 shows that the use of chemical stimulation does not cause noticeable increases in environmental impacts. Hydraulic stimulation outperforms construction of a two-legged production well in the categories human toxicity cancer effects, particulate matter/respiratory inorganics and photochemical ozone formation, whilst it underperforms in the remaining categories. For climate change category the difference between the two scenarios is minimal ( $1 \%$ of the base case impact or $\sim 0.3 \mathrm{gCO}_{2}$ eq. $/ \mathrm{kWh}$ ). Percentage increases vary between $10 \%$ and $18 \%$ for the two-legged production well scenario and between $5 \%$ and $23 \%$ for the hydraulic stimulation scenario. The scenario in which both hydraulic stimulation and two-legged well are used (besides chemical stimulation) yields impacts up to $35 \%$ higher than the base case scenario. It must be noted that hydraulic stimulation also causes substantial increases in depletion of water, and mineral, fossils and renewable resources (see Figure S3 in the

\footnotetext{
${ }^{2}$ Spacer is a fluid primarily made of water and used to support the removal of the drilling mud before cementing of the well.
} 
Supporting Information). In these categories, the scenario in which both chemical and hydraulic stimulation are carried out generates impacts $\sim 2.2$ and $\sim 1.9$ times greater than the base case scenario, respectively.

The scenarios focusing on alternative configurations for the wells pump demonstrate that impacts across all categories are reduced by $16-17 \%$ if the plant can operate without a downhole pump. The scenario in which only a reinjection pump is used also reduces the environmental impacts, but by a smaller percentage ( $6 \%)$. However, when both reinjection and downhole pumps are required, the environmental impacts increase with respect to the base case scenario by approximately $9-14 \%$.

The scenarios that envisage an increased capacity of $3 \mathrm{MW}$ of the power plant, and the cogeneration of heat and power yield the higher environmental savings with respect to the base case. Savings range from $52 \%$ for the ecotoxicity freshwater to $65 \%$ for photochemical ozone formation for the former scenario, and $55 \% \%$ for the latter.
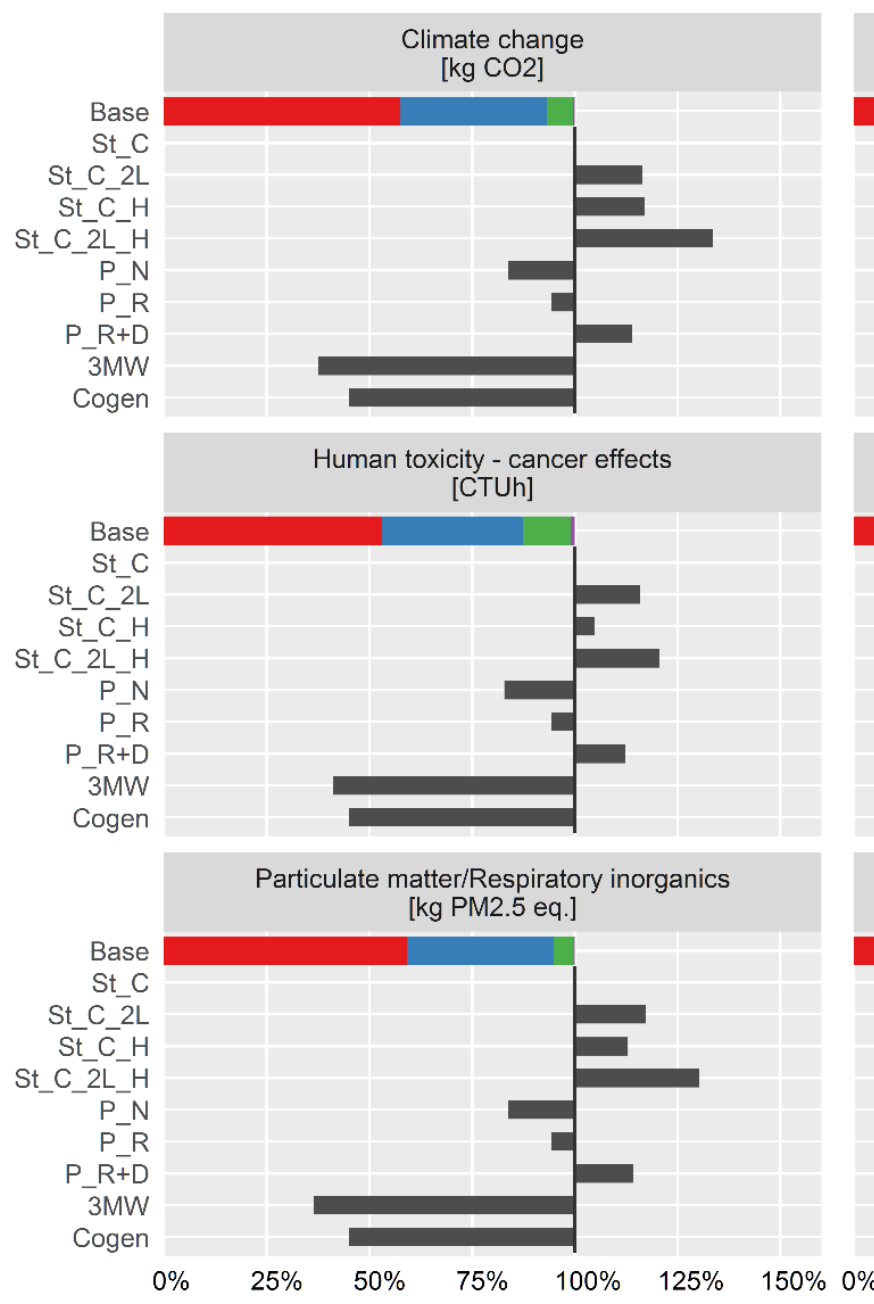

$\begin{array}{lllllll}0 \% & 25 \% & 50 \% & 75 \% & 100 \% & 125 \% & 150 \%\end{array}$
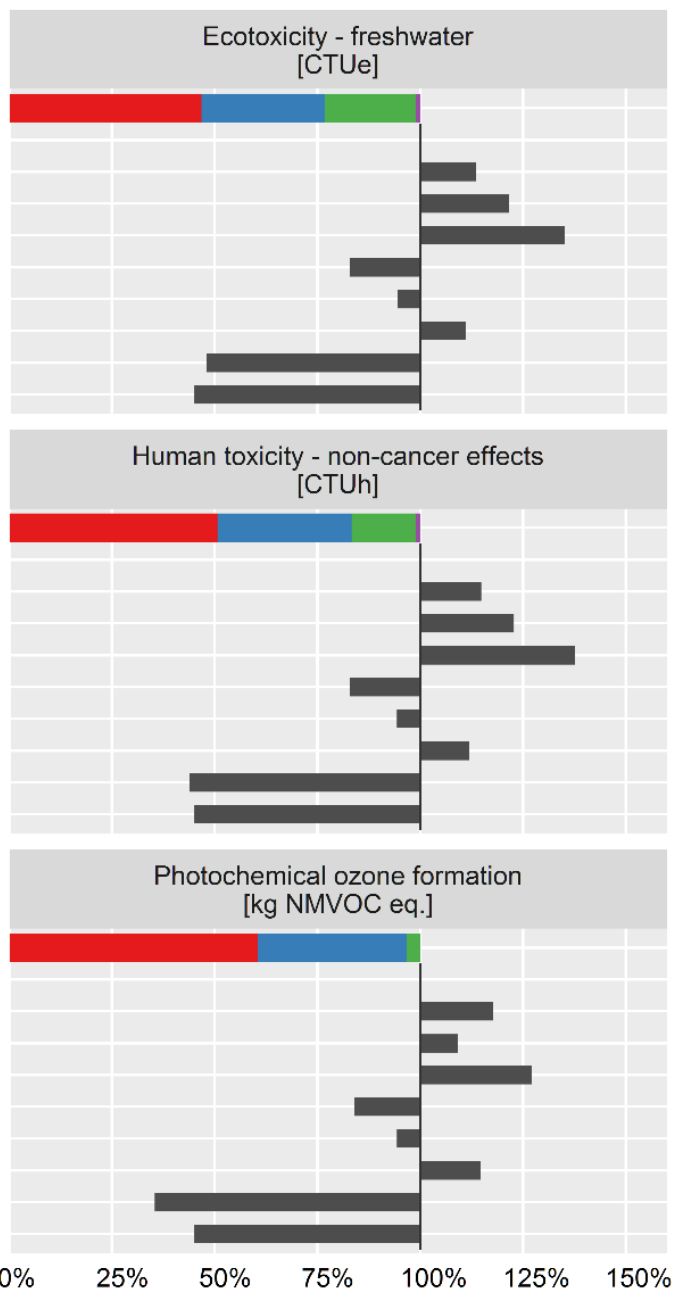

$\begin{array}{ll}\begin{array}{l}\text { Production } \\ \text { well }\end{array} & \begin{array}{l}\text { Injection } \\ \text { well }\end{array} \quad \text { Power plant }\end{array} \quad \begin{aligned} & \text { Collection } \\ & \text { pipelines }\end{aligned}$

Figure 3 - Hot spot analysis for the base case, and percentage variations for the nine alternative scenarios, for six impact categories. St_C=Chemical stimulation. St_C_L $=$ Chemical stimulation + two-legged production well; St_C_H $=$ Chemical + Hydraulic stimulation; St_C_L_H= Chemical and Hydraulic stimulation + two-legged production well; $\mathrm{P} \_\mathrm{N}=\mathrm{No}$ pumps; $\mathrm{P} \_\mathrm{R}$ $=$ Reinjection pump only; $P_{-} R+D=$ Reinjection + Downhole pump; $3 \mathrm{MW}=$ Power plant installed capacity of $3 \mathrm{MW}$; Cogen = Heat and power cogeneration. 


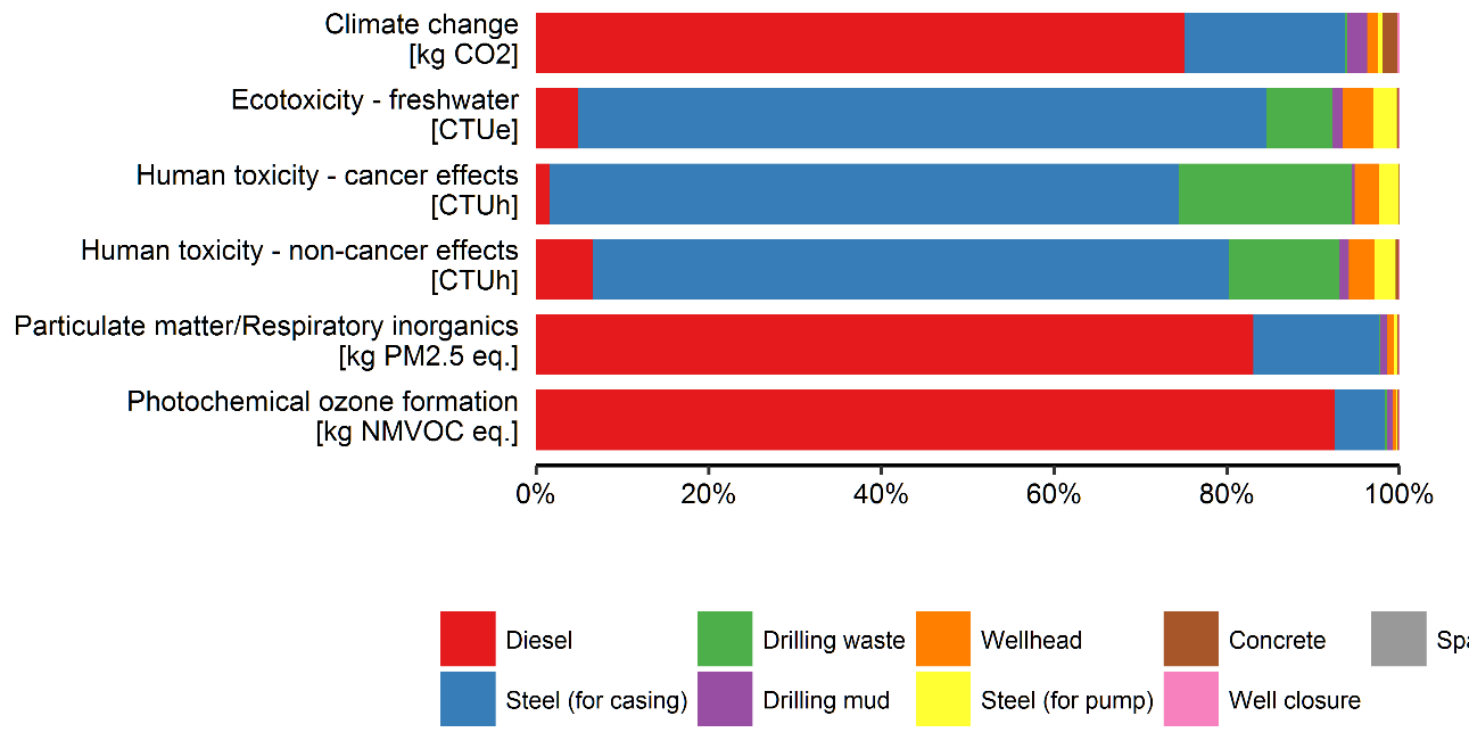

Figure 4 - Detailed hot-spot analysis for the production well, including construction and decommissioning.

\subsection{Comparison with other energy sources}

In Figure 5 we compare the normalised environmental performance (see Section 0) of UDDGP for producing electricity to other energy sources. We focus on those technologies that presently generate most of the electricity in the UK, or on those that are projected to play an increasingly important role in the near future. Within the former we include natural gas-powered combined cycle gas turbine (CCGT) and nuclear pressurised water reactors; within the latter utility-scale solar photovoltaic and offshore wind farms. We used data UK-specific data in the Ecoinvent database version 3.4 to quantify their environmental impacts (Paulillo et al., 2019c). The chart in Figure 5 reports minimum and maximum values of UDDGP scenarios; these correspond respectively to the cogeneration and chemical + hydraulic stimulation $+2^{\text {nd }}$ leg production well (see Figure 3 ) and are displayed in dark and light red.

The comparison shows that the performance of UDDGP relative to the other energy technologies depends on the scenarios and the environmental categories that are considered. In the best case scenario, electricity produced at UDDGP yield the second lowest impacts in the categories freshwater ecotoxicity and human toxicity (non-cancer effects) after natural gas; and the third lowest impacts in the climate change after nuclear and wind, and human toxicity (cancer effects) after natural gas and nuclear. However, UDDGP outperforms only solar energy in the categories particulate matter/respiratory inorganics and photochemical ozone formation. In the worst case scenario, UDDGP ranks as the third best performing technology in the categories climate change - after nuclear and wind - freshwater ecotoxicity - after natural gas and nuclear - and human toxicity non-cancer effect after natural gas and wind. In the remaining categories UDDGP results in being the worst performing technology amongst those considered.

The remaining impact categories that are included in Figure S5 in the Supporting Information show similar trade-offs: in the best case scenario, UDDGP is the best performing technology in the categories of resources depletion and the second best performing in the categories freshwater eutrophication, ionising radiations and ozone depletion; whilst in the worst case scenario, it ranks as the worst performing technology in the categories acidification, and marine and terrestrial eutrophication. 


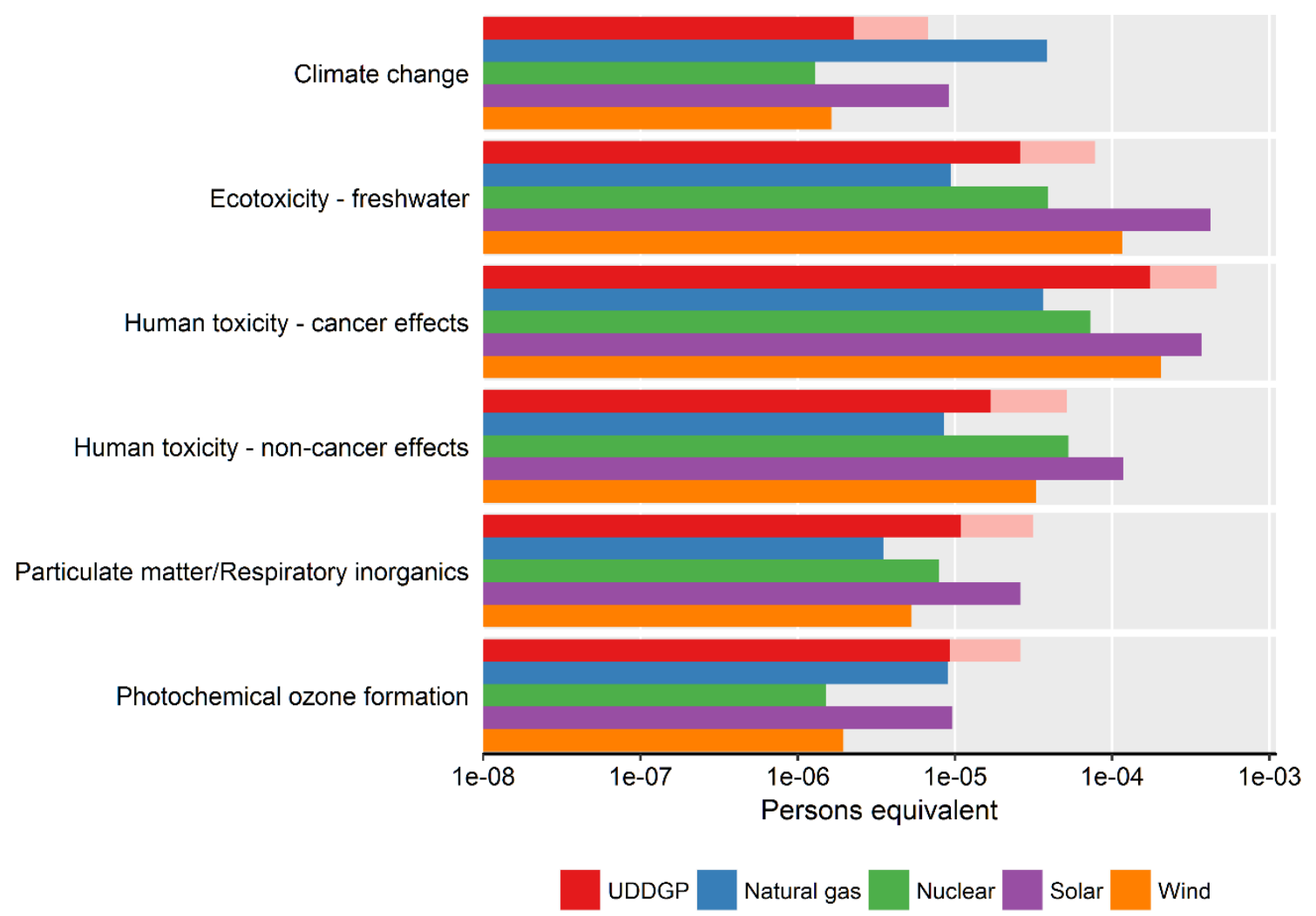

Figure 5 - Comparison of the normalised environmental impacts of $1 \mathrm{kWh}$ of electricity produced from UDDGP, as opposed to that produced by natural gas in combined cycle gas turbines, nuclear pressurised water reactors, utility-scale solar photovoltaic and offshore wind farms. For UDDGP, light red represents the maximum value and dark red the minimum value of the scenarios considered.

\subsection{Comparison of carbon intensity compared with other LCA studies}

In Figure 6 we focus on the climate change category, and compare the carbon intensity (that is the climate change impact per kWh of electricity produced) of UDDGP with that of enhanced geothermal systems quantified by three LCA studies. Lacirignola et al. (2014) and Pratiwi et al. (2018) based their study on the geothermal energy projects in the Upper Rhine Valley, known for the European funded project of Soultz-sous-Forêts (Gérard et al., 2006). Frick et al. (2010) used generic geological and technical conditions to develop several case studies. The chart in Figure 6 includes for each study values of the base case, and minimum and maximum ranges of the case studies analysed.

At $46 \mathrm{gCO}_{2}$-eq./kWh, the base case for UDDGP is enclosed between the bases case of Frick et al. ( $\sim 51$ $\mathrm{gCO}_{2}$-eq./ $\mathrm{kWh}$ ), and those of Lacirignola et al. and Pratiwi et al. (both approximately equal to $36 \mathrm{gCO}_{2}$ eq./kWh). Our minimum and maximum estimates are also comparable with those reported by these three studies. UDDG minimum estimate ( $6 \mathrm{gCO}_{2}$ eq.) is similar to that calculated by Frick et al. ( 8 $\mathrm{gCO}_{2}$ eq.), whilst the maximum estimate is about $10-20 \mathrm{gCO}_{2}$ eq. higher than those of Pratiwi et al. and Lacirignola et al., but considerably lower than that of Frick et al., which stand at $\sim 758 \mathrm{gCO}_{2}$-eq. 


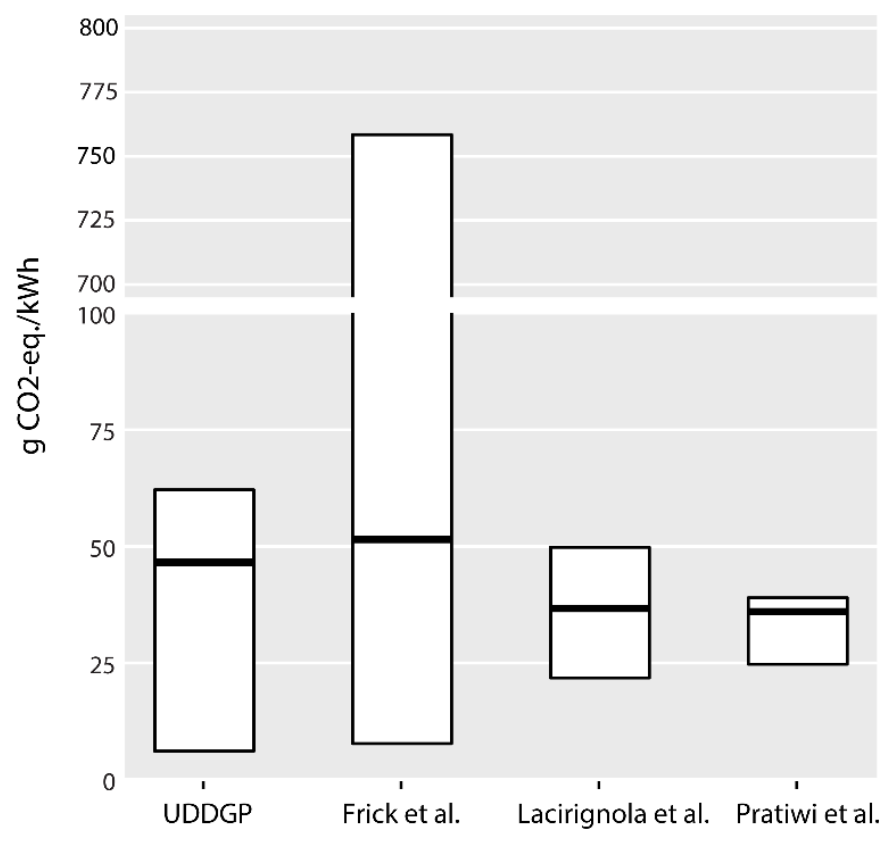

Figure 6 - Carbon intensity (i.e., climate change impacts per kWh of electricity produced) of the UDDGP project as estimated in this study, and of enhanced geothermal systems according to Frick et al. (2010), Lacirignola et al. (2014) and Pratiwi et al. (2018). The base case for Frick et al. corresponds to case study B1 ${ }^{3}$, for Lacirignola et al. to case study n. 6 and for Pratiwi et al. to case $\mathrm{S} 4$.

\section{Discussion}

The hot-spot analysis highlights that drilling the geothermal wells, and in particular the use of steel for the wells casing and the consumption of diesel for powering the drilling rig during the construction phase, represents the major source of environmental impacts for the majority of categories analysed, including those reported in the Supporting Information. This suggests two strategies for improving the environmental performance of the UDDGP project, and by extension of geothermal energy production in the UK in general. The first strategy envisages prolonging the technical life time of both the geothermal plant and the geothermal wells, which can only be achieved if the geothermal reservoir is properly managed (Rybach, 2007). A longer life time yields lower environmental impacts due to the construction phase per unit of electricity produced. The second strategy advocates either reducing consumption of diesel and steel during construction or replacing them with more sustainable alternatives. For instance, diesel consumption may be reduced by using non-contact drilling technologies (MIT, 2006; Ndeda et al., 2015), or it could be replaced by electricity where the grid mix presents a sufficient level of decarbonization (Menberg et al., 2016). Although steel consumption cannot be reduced without impairing the normal functioning of the geothermal well, the recycled content within the steel can be increased to offset the environmentally detrimental activities of ore extraction and processing - although it should be noted that the benefits of increasing recycled content depend on the end of life allocation method (Allacker et al., 2017).

Both strategies for improving the environmental performance of UDDGP are also applicable to conventional geothermal plants that exploit shallower and higher enthalpy geothermal reservoirs, but they are especially important for deep and enhanced geothermal systems that rely on substantially deeper boreholes. As an example, in Figure S6 in the Supporting Information we compare the environmental impact estimated for drilling the geothermal wells at the UDDGP project and at the

\footnotetext{
${ }^{3}$ The minimum value is calculated as the base case reduced by $85 \%$, and the maximum as $135 \%$ of the impact of the electricity mix, as reported in Fig 8 in Frick et al. (2010).
} 
Hellisheidi power plant, a conventional double flash geothermal plant in Iceland, quantified using the life cycle inventory developed by Karlsdóttir and colleagues (2015). The Hellisheidi wells are on average $2200 \mathrm{~m}$ deep, compared with $3000 \mathrm{~m}$ and $5050 \mathrm{~m}$ of UDDGP injection and production wells. Drilling the wells in the Hellisheidi plant requires approximately $100 \mathrm{~kg}$ of steel and $2 \mathrm{GJ}$ of diesel per metre of well; the correspondent requirements for the UDDGP wells are reported in Table 3. The radar chart in Figure $\mathrm{S} 6$ in the Supporting Information shows that the environmental impacts of construction and decommissioning of injection and production wells in the UDDGP project, are between $\sim 3$ and $6^{\sim}$ times higher than those of Hellisheidi in the categories climate change, photochemical zone formation and particulate matter/respiratory inorganics, whilst they are similar in the remaining three categories. The former group of categories are representative of the effect of longer boreholes. For the latter group of categories, the effect of longer boreholes is balanced by the higher use of steel per metre of well at Hellisheidi.

The environmental impacts of UDDGP are subject to considerable uncertainties because drilling of the geothermal wells and testing of the geothermal reservoir will be completed not before the end of 2019; indeed, existence and extent of the fracture system and the availability of the geothermal fluid remain to be tested. For this reason, we analysed a number of scenarios that consider the stimulation of the geothermal wells, different requirements for geo-fluid pumps, and alternative configurations of the power plant, including increased installed capacity and heat and power cogeneration.

The latter represent the most interesting scenarios. When the productivity of the geothermal reservoir is sufficiently high to support an installed capacity of $3 \mathrm{MW}$, the environmental performance per unit of electricity generated at the UDDGP plant increases substantially, for the same reasons for which it increases when the plant life time is extended. Heat and power cogeneration also increases the environmental performance of the UDDGP operation - though less substantially than an increase in capacity - because the thermal energy of the geothermal fluid is used more efficiently: the geo-fluid is reinjected at a lower temperature when cogenerating than in the case of power-only, respectively 40 and $90^{\circ} \mathrm{C}$, as estimated in our study. It should be noted that the results for the cogeneration scenario carry significant uncertainties because environmental impacts need to be allocated between the two functions of heat and electricity production. We used an exergy-based allocation strategy, but different strategies, such as those based on energy or economic considerations and the avoidedburdens approach, are likely to yield different outcomes (Frischknecht, 2000; Paulillo et al., 2019d).

In the event the permeability of the fracture system is not sufficient to achieve the target flow rate, our analysis suggests that chemical stimulation represents the most benign option. Other approaches should be attempted only when chemical stimulation is not successful. The choice between hydraulic stimulation and a two-legged production well is not straightforward, as it involves a number of tradeoffs. For climate change mitigation purposes, hydraulic stimulation only slightly outperforms construction of a two-legged production well; however, the difference is too small (and likely within the uncertainty of the results) to recommend one technology over the other. A two-legged production well circumvents the issue of low permeability by extracting the geothermal fluid from two separate sources, and crucially it is expected to reduce contentious debates concerning induced seismicity caused by hydraulic stimulation. The two-legged well strategy outperforms hydraulic stimulation in those categories in which the production of salt, used as proppant in hydraulic stimulation, yields significant contributions (e.g., human toxicity non-cancer effects and ecotoxicity), and in terms of resources depletion. Vice versa, hydraulic stimulation performs better in the categories where steel and diesel represent the major sources of impacts, i.e., photochemical ozone formation and particulate matter/respiratory inorganics. 
The configuration of wells pumps, which drive circulation of the geo-fluid between the power plant and the reservoir, substantially affects the environmental performance of the UDDGP project, primarily because the pumps reduce or increase the net production of electricity. The environmental impacts are reduced by as much as $17 \%$ if neither a downhole pump nor a reinjection pump is required; however, they increase by as much as $14 \%$ if both pumps are needed. This suggests that, where possible, pumps should be avoided and that, under equal conditions, geothermal fields with self-flowing wells should be preferred over those that require pumped wells. These results are based on generic estimates for the pumps' specific electricity consumption, but it must be noted that the actual consumption may vary substantially depending on local conditions (Lacirignola et al., 2014).

To evaluate the potential environmental benefits of geothermal energy in the UK, we compared UDDGP with other technologies key to the present and future of UK power generation industry. We first focus on the climate change category because it is the main driving force behind the development of renewable and alternative technologies. Our analysis shows that electricity produced from the geothermal source in the UK substantially outperforms natural gas burnt in a combined cycle plant ( $\sim 50 \mathrm{~g} \mathrm{CO}_{2}$-eq.) but also utility-scale solar photovoltaic ( $\sim 5 \mathrm{~g} \mathrm{CO}_{2}$-eq.), whilst being competitive with the performances of nuclear pressurised water reactors and offshore wind farms ( $15 \mathrm{~g} \mathrm{CO}_{2}$-eq.) depending on the scenario considered. Hence, where available geothermal energy should be given priority over, or at least receive as much consideration as solar energy for meeting national and international carbon emissions targets; much so if we note that unlike solar and wind, geothermal energy represents a baseline, dispatchable source of energy that is independent from climatic conditions.

However, the environmental benefits of geothermal energy are not straightforward if other environmental problems are taken into account. For instance, geothermal energy scores very well in the categories ecotoxicity and resources depletion - even when hydraulic stimulation is carried out but it is amongst the worst performing energy sources for the particulate matter/respiratory inorganics impacts.

Finally, to validate our model, we compared our results with those of other LCA studies on enhanced geothermal systems (Section 3.3). We restricted the comparison to the climate change category because very few studies assess environmental categories other than that. The comparison shows that our results are in line with base cases of Lacirignola and Blanc (2013), Pratiwi et al. (2018), and Frick et al. (2010). Our minimum estimate, which correspond to a cogeneration scenario, is similar to that of Frick et al; whilst our maximum estimate, which envisages deployment of all three stimulation techniques considered, is enclosed within those of Lacirignola and Blanc (2013), Pratiwi et al. (2018) and that of Frick et al. (2010). Notably, the maximum range quantified by Frick et al. (2010) is considerably higher than ours because the Authors explored worst-case scenarios also with respect to thermal gradient and efficiency of the ORC cycle. However, the positive comparison suggests our analysis is consistent with others.

\section{Conclusions}

When completed, the United Downs Deep Geothermal Power project (UDDGP) will be the first geothermal plant ever to be commissioned in the United Kingdom; the project represents a considerable advancement for the energy sector in the country. This article presents a comprehensive and detailed Life Cycle Assessment (LCA) study using site-specific data to quantify the potential environmental impacts of the UDDGP project in particular, and of geothermal energy in the UK in general, in terms of a base case and nine alternative scenarios. The results are consistent with the few available LCA results for enhanced geothermal plants across the world. 
The hot spot analysis revealed that the greatest portion of environmental impacts originates in the construction phase, in particular from steel used for the wells casing and diesel consumed during drilling. Therefore, strategies to improve the environmental efficiency of deep geothermal should at first focus on extending the lifetime and reducing or replacing with more sustainable alternative diesel and steel.

The scenarios developed to address uncertainties on geological conditions and final configuration of the power plant highlight that i) both an increase in the installed capacity from 1 to $3 \mathrm{MW}$ and cogeneration of heat and power can substantially increase the environmental performance; ii) whilst chemical stimulation yields negligible contributions to the environmental footprint, both hydraulic stimulation and construction of a two-legged well can each increase the environmental impacts by 10-20\%; and iii) different configurations of wells pumps significantly affect the environmental performance, suggesting that, when possible, pumps should be avoided.

The results allowed us to compare the environmental performance of the UDDGP project, and by extension of the UK geothermal energy, against other energy sources. The comparison highlighted clear trade-offs between environmental categories. Based on our results, geothermal energy should be the third most environmentally benign option after nuclear pressurised water reactors and wind offshore farms, if the ultimate objective is reducing carbon emissions.

Future work should focus on evaluating in detail the merits of the strategies mentioned above to reduce the environmental impacts of geothermal energy.

\section{Acknowledgments}

This work is part of the S4CE collaborative project, which has received funding from the European Union's Horizon 2020 research and innovation programme under grant agreement number 764810.

\section{References}

Allacker, K., Mathieux, F., Pennington, D., Pant, R., 2017. The search for an appropriate end-of-life formula for the purpose of the European Commission Environmental Footprint initiative. Int. J. Life Cycle Assess. doi:10.1007/s11367-016-1244-0

Benini, L., Mancini, L., Sala, S., Schau, E., Manfredi, S., Pant, R., 2014. Normalisation method and data for Environmental Footprints. doi:10.2788/16415

Bravi, M., Basosi, R., 2014. Environmental impact of electricity from selected geothermal power plants in Italy. J. Clean. Prod. 66, 301-308. doi:10.1016/j.jclepro.2013.11.015

Busby, J., Terrington, R., 2017. Assessment of the resource base for engineered geothermal systems in Great Britain. Geotherm. Energy 5. doi:10.1186/s40517-017-0066-z

Clift, R., Doig, A., Finnveden, G., 2000. The Application of Life Cycle Assessment to Integrated Solid Waste Management. Part 1 - Methodology. Process Saf. Environ. Prot. 78, 279-287. doi:10.1205/095758200530790

Curran, M.A., Mann, M., Norris, G., 2005. The international workshop on electricity data for life cycle inventories, in: Journal of Cleaner Production. pp. 853-862. doi:10.1016/j.jclepro.2002.03.001

Doka, G., 2003. Life Cycle Inventories of Waste Treatment Services. ecoinvent report No. 13. Part III: Landfills - Underground Deposits - Landfarming.

Finnveden, G., Hauschild, M.Z., Ekvall, T., Guinee, J.B., Heijungs, R., Hellweg, S., Koehler, A., Pennington, D., Suh, S., 2009. Recent developments in Life Cycle Assessment. J. Environ. Manage. 
91, 1-21. doi:10.1016/j.jenvman.2009.06.018

Frick, S., Kaltschmitt, M., Schröder, G., 2010. Life cycle assessment of geothermal binary power plants using enhanced low-temperature reservoirs. Energy 35, 2281-2294. doi:10.1016/j.energy.2010.02.016

Frischknecht, R., 2000. Allocation in Life Cycle Inventory Analysis for joint production. Int. J. Life Cycle Assess. doi:10.1007/BF02979729

Gérard, A., Genter, A., Kohl, T., Lutz, P., Rose, P., Rummel, F., 2006. The deep EGS (Enhanced Geothermal System) project at Soultz-sous-Forêts (Alsace, France). Geothermics. doi:10.1016/j.geothermics.2006.12.001

Hauschild, M.Z., Rosenbaum, R.K., Olsen, S.I., 2017. Life Cycle Assessment: Theory and Practice. Springer International Publishing. doi:10.1007/978-3-319-56475-3

IEA, 2018. World Energy Outlook 2018. doi:10.1787/weo-2018-en

ISO, 2006a. Environmental Management - Life Cycle Assessment - Principles and Framework. EN ISO 14040:2006.

ISO, 2006b. Environmental Management - Life Cycle Assessment - Requirements and guidelines. EN ISO 14044:2006.

JRC, 2012. Characterisation factors of the ILCD Recommended Life Cycle Impact Assessment methods: database and supporting information, European Commission. European Commission Joint Research Centre. doi:10.2788/60825

JRC, 2011. Recommendations for Life Cycle Impact Assessment in the European context - based on existing environmental impact assessment models and factors. doi:10.278/33030

Karlsdóttir, M.R., Pálsson, Ó.P., Pálsson, H., Maya-Drysdale, L., 2015. Life cycle inventory of a flash geothermal combined heat and power plant located in Iceland. Int. J. Life Cycle Assess. 20, 503519. doi:10.1007/s11367-014-0842-y

Lacirignola, M., Blanc, I., 2013. Environmental analysis of practical design options for enhanced geothermal systems (EGS) through life-cycle assessment. Renew. Energy 50, 901-914. doi:10.1016/j.renene.2012.08.005

Lacirignola, M., Meany, B.H., Padey, P., Blanc, I., 2014. A simplified model for the estimation of lifecycle greenhouse gas emissions of enhanced geothermal systems. Geotherm. Energy 2, 1-19. doi:10.1186/s40517-014-0008-y

Ledingham, P., Cotton, L., Law, R., 2019. The United Downs Deep Geothermal Project, in: 44th Workshop on Geothermal Reservoirs Engineering.

Lu, S.M., 2018. A global review of enhanced geothermal system (EGS). Renew. Sustain. Energy Rev. 81, 2902-2921. doi:10.1016/j.rser.2017.06.097

Menberg, K., Pfister, S., Blum, P., Bayer, P., 2016. A matter of meters: State of the art in the life cycle assessment of enhanced geothermal systems. Energy Environ. Sci. 9, 2720-2743. doi:10.1039/c6ee01043a

MIT, 2006. The Future of Geothermal Energy. doi:10.1080/17461391.2012.683813

Nami, P., Schellschmidt, R., Schindler, M., Tischner, T., 2008. Chemical Stimulation Operations for Reservoir Development of the Deep Crystalline Hdr/Egs System At Soultz-Sous-Forêts (France). 32nd Work. Geotherm. Reserv. Engeneering Stanford Univ. 325-333. 
Ndeda, R., Sebusang, E., Marumo, R., Ogur, E., 2015. Review of thermal surface drilling technologies. Proc. Sustain. Res. Innov. Conf.

Parisi, M.L., Ferrara, N., Torsello, L., Basosi, R., 2019. Life cycle assessment of atmospheric emission profiles of the Italian geothermal power plants. J. Clean. Prod. doi:10.1016/j.jclepro.2019.06.222

Parker, R.H., 1989. Hot Dry Rock Geothermal Energy, Phase 2B Final Report of the Camborne School of MInes Project. Pergamon Press.

Paulillo, A., 2018. Operationalising the use of Life Cycle Assessment to nuclear waste management. PhD Thesis. University College London.

Paulillo, A., Clift, R., Dodds, J.M., Milliken, A., Palethorpe, S.J., Lettieri, P., 2019a. Radiological Impact Assessment in Life Cycle Assessment. Part I: General framework and two practical methodologies. Sci. Total Environ.

Paulillo, A., Clift, R., Dodds, J.M., Milliken, A., Palethorpe, S.J., Lettieri, P., 2019b. Radiological Impact Assessment in Life Cycle Assessment. Part II: Comparison of Methodologies. Sci. Total Environ.

Paulillo, A., Cotton, L., Law, R., Striolo, A., Lettieri, P., 2019c. Inventory and results from Life Cycle Assessment study on electricity production at the United Downs Deep Geothermal Power project. Data $\mathrm{Br}$.

Paulillo, A., Striolo, A., Lettieri, P., 2019d. The environmental impacts and the carbon intensity of geothermal energy: A case study on the Hellisheiði plant. Environ. Int. 133(Pt B). doi:10.1016/j.envint.2019.105226

Pizzol, M., Christensen, P., Schmidt, J., Thomsen, M., 2011. Impacts of "metals" on human health: A comparison between nine different methodologies for Life Cycle Impact Assessment (LCIA). J. Clean. Prod. doi:10.1016/j.jclepro.2010.05.007

Pratiwi, A., Ravier, G., Genter, A., 2018. Life-cycle climate-change impact assessment of enhanced geothermal system plants in the Upper Rhine Valley. Geothermics 75, 26-39. doi:10.1016/j.geothermics.2018.03.012

Rogge, S., 2004. Geothermische Stromerzeugung in Deutschland e Ökonomie. Ökologie und Potenziale. Technische Universität Berlin.

Rybach, L., 2007. Geothermal Sustainability. Ghc Bull. 1-7. doi:10.1046/j.0956-540x.2001.01558.x

Sandén, B. a., 2007. Standing the Test of Time: Signals and Noise From Environmental Assessments of Energy Technologies, in: Proceedings of SETAC Europe 14th LCA Case Studies Symposium "LCA of Energy, Energy in LCA." doi:10.1557/PROC-1041-R05-06

Sandén, B.A., Jonasson, K.M., Karlström, M., Tillman, A.-M., 2005. LCA of Emerging Technologies : a Methodological Framework, in: Proceedings of LCM2005. Barcelona.

Schindler, M., Baumgärtner, J., Gandy, T., Hauffe, P., Hettkamp, T., Menzel, H., Penzkofer, P., Teza, D., Tischner, T., Wahl, G., 2010. Successful hydraulic stimulation techniques for electric power production in the Upper Rhine Graben, Central Europe. Proc. World Geotherm. Congr. 1-7.

SKM Consulting, 2011. Geothermal Potential in Great Britain and Northern Ireland.

Sullivan, J.L., Clark, C.E., Han, J., Wang, M., 2010. Life-Cycle Analysis Results of Geothermal Systems in Comparison to Other Power Systems, Argonne National Laboratory. doi:10.2172/993694

Sullivan, J.L., Clark, C.E., Yuan, L., Han, J., Wang, M., 2011. Life-Cycle Analysis for Geothermal Systems in Comparison to Other Power Systems: Part II. 
Tomasini-Montenegro, C., Santoyo-Castelazo, E., Gujba, H., Romero, R.J., Santoyo, E., 2017. Life cycle assessment of geothermal power generation technologies: An updated review. Appl. Therm. Eng. 114, 1119-1136. doi:10.1016/j.applthermaleng.2016.10.074

Treyer, K., Oshikawa, H., Bauer, C., Miotti, M., 2015. WP4: Environment, in: Hirschberg, S., Wiemer, S., Burtherr, P. (Eds.), Energy from the Earth. Deep Geothermal as a Resource for the Future?

UNFCCC, 2015. Adoption of the Paris Agreement. FCCC/CP/2015/L.9/Rev.1. doi:FCCC/CP/2015/L.9/Rev.1

Wernet, G., Bauer, C., Steubing, B., Reinhard, J., Moreno-Ruiz, E., Weidema, B., 2016. The ecoinvent database version 3 (part I): overview and methodology. Int. J. Life Cycle Assess. 21, 1218-1230. doi:10.1007/s11367-016-1087-8 